This is the author's Post-print version (final draft post-refereeing as accepted for publication by the journal). The definitive, peer-reviewed and edited version of this article is published as: Permentier M., van Ham M. and Bolt G. (2009) Neighbourhood reputation and the intention to leave the neighbourhood. Environment and Planning A 41, 2162-2180 http://dx.doi.org/10.1068/a41262

\title{
Neighbourhood reputation and the intention to leave the neighbourhood
}

\author{
Matthieu Permentier*, Maarten van Ham** \& Gideon Bolt***
}

*\&***Utrecht University, Urban and Regional research centre Utrecht (URU), Utrecht University, P.O. Box 80115, 3508 TC Utrecht, The Netherlands. Phone: +3170-3407537, e-mail: *m.permentier@geo.uu.nl and m.permentier@scp.nl, ***g.bolt@geo.uu.nl

**University of St Andrews, Centre for Housing Research (CHR), School of Geography \& Geosciences, Irvine Building, North Street, St Andrews, Fife, KY16 9AL, UK. Phone +44(0)1334 463912, Fax +44 (0)1334 463949, e-mail: maarten.vanham@st-andrews.ac.uk

\begin{abstract}
Moving intentions are likely not only to be affected by whether or not residents are satisfied with their neighbourhood, but also by how they think that other city residents assess their neighbourhood: the perceived reputation of the neighbourhood. The place where one lives is a reflection of one's position in society and therefore people might want to leave neighbourhoods with a poor reputation even if they are satisfied with their residential environment. Using data from a specifically designed survey in 24 Dutch neighbourhoods, we tested the hypothesis that in addition to neighbourhood satisfaction, perceived neighbourhood reputations are an important predictor of the intention to leave the neighbourhood. The results show that the perceived neighbourhood reputation is indeed a significant predictor of moving intentions, even after controlling for neighbourhood satisfaction and neighbourhood attachment. This finding suggests that neighbourhood regeneration policy should not only focus on improving residents' neighbourhood satisfaction, but also on improving the perceived reputation of neighbourhoods.
\end{abstract}

\section{Introduction}

An increasing body of literature underlines the relevance of neighbourhood characteristics in understanding both moving intentions and actual moving behaviour (Clark et al., 2006; Feijten and Van Ham, forthcoming; Kearns and Parkes, 2003; Lee et al., 1994; Lu, 1998; Parkes and Kearns, 2003; Van Ham and Feijten; 2008; Van Ham and Clark, forthcoming). Recent attention for urban neighbourhoods, and especially neighbourhood (dis)satisfaction, is linked to policy makers search for factors contributing to the success of neighbourhood regeneration (Parkes et al., 2002). More insight in the role of neighbourhood characteristics in understanding factors triggering residential mobility behaviour can contribute to evidence based policy to improve the liveability of urban neighbourhoods and helps to create more stable neighbourhoods. 
Moving intentions are likely not only to be affected by whether or not residents are satisfied with their neighbourhood, but also by how they think that other city residents assess their neighbourhood: the perceived reputation of the neighbourhood. The self-image of people is strongly affected by the way they believe others see and think of them and the groups they belong to (Goffman, 1963; Mead, 1934; Ridgeway, 2006). Repeatedly, studies have found an effect of negative neighbourhood reputations on the self-image of residents of infamous neighbourhoods (Bush et al., 2001; Hastings and Dean, 2003; Taylor, 1998; Wacquant, 1993). The impact of the neighbourhood's reputation on the self has to be placed in a context in which neighbourhoods function increasingly as status symbols. The place where one lives is a reflection of one's position in society and one's preferences (Bourdieu, 1984; Forrest and Kearns, 2001). If people believe their status suffers from group membership - living in a certain neighbourhood - they will try to disassociate themselves from that group and the stigma associated with group membership. Those living in neighbourhoods with a poor (perceived) reputation can therefore be expected to be more likely to have the intention to leave their neighbourhood than people living in neighbourhoods with a good reputation. This might even be the case when people themselves are perfectly satisfied with their neighbourhood (Permentier et al., 2007).

This paper aims to contribute to a better understanding of the role of (perceived) neighbourhood characteristics in individual residential mobility behaviour. We hypothesise that, in addition to neighbourhood satisfaction, the perceived reputation of the neighbourhood is an important predictor of the intention to leave the neighbourhood. We focus explicitly on perceived reputations because within the behavioural model we assume, perceived reputations are more appropriate than 'objective' measures of neighbourhood reputations. Characteristics of the residential context are important in mobility decision models insofar as they are perceived, evaluated and experienced by residents (Lee et al., 1994). More knowledge of the impact of neighbourhood reputations on residential mobility behaviour is important as individual mobility decisions are responsible for the sorting of households into different neighbourhoods. The underlying mechanisms of this sorting process might give us important cues for the success of urban renewal projects. If perceived reputation triggers moving intentions, improving the neighbourhood satisfaction of residents will most likely be insufficient to transform deprived neighbourhoods into attractive places to live. To be successful, neighbourhoods should also have a good - or at least not a bad - reputation.

This study uses data from a survey that was specifically designed to investigate neighbourhood reputations and their impact on the behaviour of residents. The survey, including 1,339 residents in 24 different neighbourhoods, was carried out in the spring of 2006 in the city of Utrecht, The Netherlands.

\section{Literature review}

The residential mobility literature offers various models to understand moving intentions or thoughts (Brown and Moore, 1970; Galster, 1987; Lee et al., 1994). In most of these models moving intentions are seen as a response to residential stress and moving intentions precede actual moving behaviour (Speare et al., 1975). Actual mobility behaviour only occurs when there are no restrictions or constraints preventing an intention from being realized. If we would look at actual moving behaviour, we would miss all those people who have the intention to leave their neighbourhood, but are unable to do so because of housing market constraints and the direct and indirect monetary and non-monetary costs involved in moving. Studying 
moving intentions provides a direct insight in how neighbourhood reputations affect mobility decisions (Van Ham and Feijten, 2008).

Theoretical models on moving intentions do generally include individual and household characteristics, and subjective neighbourhood evaluations such as neighbourhood satisfaction. Recent studies have shown that also more objective neighbourhood characteristics, such as the ethnic and socio-economic composition of the neighbourhood population, have an impact on mobility decisions (Clark et al., 2006; South et al., 2005; Van Ham and Feijten, 2008;). Research on neighbourhood reputations revealed that the same neighbourhood characteristics also impact on the external reputation ${ }^{1}$ of neighbourhoods (Permentier et al., 2008). In this paper we study the impact of neighbourhood reputations as perceived by residents on the intention to leave their neighbourhood.

Below we first discuss the effects of neighbourhood satisfaction and perceived reputation on moving intentions. Next we discuss the effects of neighbourhood attachment and participation in the neighbourhood. Although this study aims to understand why people intend to leave their neighbourhood, we include a discussion of a set of control variables found in the literature which are known to have an effect on residential mobility behaviour in general. It is very likely that there is substantial overlap between the factors which influence people's intention to leave the neighbourhood and factors influencing moving behaviour.

\section{Neighbourhood satisfaction and perceived reputation}

Neighbourhood (dis)satisfaction is often mentioned as one of the key predictors of moving intentions (Clark and Ledwith, 2006; Lee et al., 1994; Lu, 1998). According to Speare's classical study (1974) residential satisfaction is a significant predictor of moving even when controlling for socio-demographic characteristics of the residents (age, household composition). Speare argued that these socio-demographic characteristics only have a very limited direct impact on moving intentions because socio-demographic characteristics are mediated through residential satisfaction. Parkes and Kearns (2003) found that people who are dissatisfied with the overall quality of their neighbourhood are more likely to have an intention to move than people who are satisfied (see also Lee et al., 1994; Lu, 1998). Though these more recent studies acknowledge that neighbourhood satisfaction is still a very important predictor, they find, in contrast to Speare, that socio-demographic variables have an independent effect on moving intentions (Lee et al., 1994; Lu, 1998).

As argued in the introduction, besides the assessment of the neighbourhood by residents themselves, also the assessments of the neighbourhood by other city residents can play a role in shaping people's intention to leave their neighbourhood. Mead (1934) has argued that the self-image of people is influenced by the way they think that others think of them and the group they belong to (see also Festinger, 1954; Goffman, 1963; Ridgeway 2006). Living in a neighbourhood with a poor perceived reputation can have a negative effect on the self-image of individuals, even when they are generally satisfied with their neighbourhood. Ultimately, ideas about how outsiders see a neighbourhood may lead to people's intention to leave the neighbourhood. Only a limited number of studies have recognized the potential importance of an area's reputation (Tsfati and Cohen, 2003). This is surprising, since many academics stress the function that the residential address has as an indicator of the social status of an individual (Coleman and Neugarten, 1972; Firey, 1945; Forrest and Kearns, 2001; Suttles, 1972). The neighbourhood is more than just the location of the dwelling: it as a consumption good, symbolizing an individual's prestige (Bourdieu, 1984). Moving to a neighbourhood with a better reputation can improve a

\footnotetext{
${ }^{1}$ Measured as the average reputation-rating of urban neighbourhoods by other city residents.
} 
person's individual status and self-image and consequently their general well-being. However not all residents will necessarily react in a similar fashion to neighbourhood reputations. For example, some residents of stigmatized areas may avoid or simply deny the stigma of the neighbourhood.

The concepts of neighbourhood satisfaction and perceived neighbourhood reputation can be expected to overlap (Curtis and Jackson, 1977; Permentier et al., 2007) and share some determinants. However, research by Permentier and colleagues (2007) has shown that this overlap is limited: the concepts of satisfaction and perceived neighbourhood reputation are complementary rather than similar in meaning. Residents may be satisfied with their neighbourhood, but still perceive the reputation of this neighbourhood to be negative. Residents might be satisfied with a neighbourhood with a poor reputation because they selected themselves into this neighbourhood in the first place, but also because of the tendency of residents to think more positively about their residential environment when they lack the opportunity to move somewhere else. These mechanisms are less likely to have an impact on the perception of a neighbourhood's reputation. How residents perceive the reputation of their neighbourhood is strongly correlated with the reputation that outsiders hold of the neighbourhood (Permentier et al., 2008). These outsiders have no interest in downplaying the negative aspects of an area and are likely to base their opinion on a limited set of objective neighbourhood characteristics rather than personal evaluations (Permentier et al., 2008).

To our knowledge there are no studies simultaneously studying the effect of neighbourhood satisfaction and perceived reputation on intentions to leave the neighbourhood. We found one paper by Tsfati and Cohen (2003) including both concepts in a study of plans to leave town. They found that residents who perceive the reputation of their town to be negative are more likely to have plans to leave town, even when controlling for satisfaction with different attributes of the town. A move out their town was thought to improve their status and subsequently their self-esteem. The study by Tsfati and Cohen (2003) does not deal with the fact that people are not randomly sorted into towns but select themselves into towns according their preferences and resources. People who find the reputation of their town important are less likely to decide to live in a town with a poor reputation. It can be expected that this mechanism of self-selection decreases the effect of perceived reputation on moving intentions.

Self-selection can affect moving intentions in two ways. First, the degree of choice people had in selecting their dwelling and neighbourhood is likely to have an impact on moving intentions. It can be argued that individuals who perceived a high degree of choice when they selected their neighbourhood, are less likely to want to leave the neighbourhood compared to individuals who were limited in their choice of residency. It should be noted that people with little choice may be less likely to have an intention to move as a result of a poor neighbourhood reputation due to their poor prospects in the housing market (see Festinger, 1957 on cognitive dissonance reduction). Second, people who are very status-conscious are likely to have already selected themselves into a neighbourhood with a good reputation which positively reflects on their self-image (see De Jong and Fawcett, 1981). Those less affected by status considerations are also less likely to select a neighbourhood based on its reputation.

\section{Neighbourhood characteristics}

Objective neighbourhood characteristics have been found to impact residents' intention to leave their neighbourhood (SCP, 2007; Taub et al., 1984; Van Ham and Feijten, 2008;but see Kearns \& Parkes, 2003 and Lee et al., 1994 for no effects). The 
literature distinguishes physical neighbourhood characteristics, and socio-economic and socio-demographic characteristics (Amérigo, 2002). Housing density can be seen as an important physical characteristic since it is an indicator of green spaces, environmental stress and housing stock. The majority of people prefer low-density environments, while only a small proportion of people prefer to live high-density urban environments. Mohan and Twigg (2007) found that population density has a negative impact on neighbourhood desirability. Van Ham and Feijten (2008) and Van Ham and Clark (forthcoming) found that residents of (strongly) urbanized areas are more likely to have a moving wish than residents of non-urbanized or weakly urbanized areas.

Several studies have found that people living in a neighbourhood with a low socio-economic status are more likely to have the wish to leave their neighbourhood than people living in neighbourhoods with a high socio-economic status (Van Ham and Clark, forthcoming; Van Ham and Feijten, 2008). People generally avoid neighbourhoods with a low socio-economic status (Harris, 1999; Quillian, 2003) because of the (perceived) negative effects of living in such neighbourhoods (see Buck, 2001; Overman, 2002). Moreover, the reputation of a neighbourhood is positively influenced by the socio-economic status of its residents (Logan and Collver, 1983; Musterd, 2008).

A high percentage of ethnic minorities in a neighbourhood is found to be positively linked to moving wishes, intentions and actual moving behaviour. Crowder (2000) found for the US that the percentage of ethnic minorities in a neighbourhood has a positive effect on leaving the neighbourhood among white respondents. Similar results were found for the Netherlands, even after controlling for the socio-economic status of neighbourhoods (Van Ham and Clark, forthcoming).

\section{Neighbourhood attachment and neighbourhood participation}

Residents who are strongly attached to their neighbourhood may be more reluctant to leave than residents who lack such attachment (Guest et al., 2006; Temkin and Rohe, 1998; Van Vugt et al., 2003). Neighbourhood attachment resembles the loyaltycomponent of Hirschman's 'Exit, voice and loyalty' framework (1970). Originally this work studied the responses of consumers to a decline in the quality of consumer goods. Two types of responses were distinguished: exit and voice. Consumers who 'exit' stop buying a product or leave a certain organisation, while 'voice' is an expression of dissatisfaction directed to the management of a company or organisation. According to Hirschman the choice for one of these two responses is affected by loyalty, where loyalty can be understood as being attached to a product or organization. Loyalty holds exit at bay and activates voice (Hirschman, 1970).

In the context of residential mobility studies, neighbourhood attachment (loyalty) and neighbourhood participation (voice) are both factors that are likely to impact moving intentions (the intention to exit the neighbourhood). Both loyalty and voice require some level of investment in the neighbourhood. People who feel attached to their neighbourhood and who participate to improve the neighbourhood have made a psychological and social investment which can be expected to decrease the probability to leave (Lee et al., 1994; Taub et al., 1984; Van Vugt et al., 2003). Residents who have not invested in their neighbourhood are the most likely to have an intention to leave their neighbourhood.

In this study we make the concept of loyalty operational by equating loyalty to neighbourhood attachment. Two dimensions of neighbourhood attachment can be discerned: an emotional/attitudinal dimension and a functional/behavioural dimension (Bolan, 1997). Emotional attachment refers to the psychological ties residents have with their immediate living environment and its residents (Blokland, 2000; Dekker 
and Bolt, 2005). This way attachment can lead to a feeling of security, build selfesteem, give a bond to people, and maintain group identity (Dekker, 2007). A high degree of emotional attachment to the neighbourhood can be expected to lower the probability that people develop moving intentions (see Ahlbrandt and Cunningham, 1979). Functional attachment refers to the number of contacts that residents have within their neighbourhood and the nature of these relationships (e.g. intensity of contact). Clark and Ledwith (2006) found that residents who perceived their neighbourhood to be close-knit were the least likely to express moving plans, even after controlling for general neighbourhood satisfaction. In other studies it was found that having contacts within a neighbourhood has a negative effect on moving intentions (Ahlbrandt and Cunningham, 1979; Boehm, 1981). Bolt and Torrance (2005) found a weak, but similar negative effect of the number of social contacts on the intention to leave the neighbourhood.

The voice concept is made operational through active participation in formal neighbourhood organisations. This is a specific type of participation because it has the neighbourhood as the focus of interest whereas other types of clubs/organisations might be based in the neighbourhood but do not have the neighbourhood as focus of interest. Residents who actively participate in formal neighbourhood organisations can be expected to be less likely to express moving intentions than residents who do not participate. ${ }^{2}$ This is because the former group has invested in their neighbourhood. Another reason why participation is negatively related to moving intentions is that participation can generate functional attachment (which in its turn lowers the intention to move). A limited number of studies have studied the impact of participation on residential mobility and found that local participation does lower the intention to move (Sharp, 1984). Results of a study on the neighbourhood level by Guest and colleagues (2006) found that neighbourhood participation was positively associated with residential stability.

\section{Control variables: individual, household and dwelling characteristics}

In our models we control for several variables found to affect residential mobility decisions (see Clark and Dieleman, 1996): age, gender, household composition, ethnicity, level of education, employment status, income and tenure. Most literature reports clear age effects on moving intentions: as people get older, they are less likely to express an intention to move (Boehm, 1981; Lee et al., 1994, but see Kearns and Parkes, 2003 for no age-effect). Young people are the most likely to have the intention to move as they experience many changes in their educational, labour and household career and therefore the need arises to adjust their housing situation. Lee and colleagues (1994) found that women are more likely to express an intention to move than men.

Singles are often found to have a high probability to express moving intentions as they are more likely not yet to have settled permanently. In contrast, couples with children are the least mobile because they are likely to have found a dwelling and neighbourhood that suit their aspirations (Clark and Dieleman, 1996; Kearns and Parkes, 2003). Ethnic minorities are often found to be living in poor quality housing and deprived neighbourhoods and thus are more likely to have a moving intention (Lee et al., 1994). Some studies (for example Clark and Ledwith, 2006) find no effect of ethnicity on moving intentions after controlling for housing and neighbourhood quality or even found a negative effect of ethnicity (Bolt and Van Kempen, 2002; South and Deane, 1993). The negative effect might be caused by the strong ties that

\footnotetext{
${ }^{2} \mathrm{We}$ acknowledge that this type of formal participation is not necessarily due to dissatisfaction, but can also be simply a resultant of the wish to be involved in organising neighbourhood activities, such as a street barbecue.
} 
ethnic minorities might have to their ethnic community (Bowes et al., 2002; Freeman, 2000), but also by the barriers that ethnic minorities face on the housing market. Discrimination by actors on the housing market, like mortgage lenders, real estate agents and (social) landlords, as well as fear of racial harassment outside the ethnic communities may reduce the (perceived) moving options among ethnic minorities (Galster, 1999; Krysan and Farley, 2002; Phillips, 1998; Yinger, 1999).

Income has been found to be positively related to moving intentions (Ahlbrandt and Cunningham, 1979; Mulder, 1993). According to Clark and Ledwith (2006) high income households face fewer constraints compared to low-income households. Furthermore, higher income occupations are associated with job related moves (Van Ham, 2002). Also being in employment and having a high level of education are found to be positively related to moving intentions. Owner-occupants are found to be less likely to have moving intentions than renters. Homeowners face high costs when they move in the Netherlands (mainly stamp duty) and are more likely than renters to be satisfied with their current dwelling and neighbourhood (Parkes and Kearns, 2003; Van Ham and Feijten, 2008).

Dwelling characteristics, such as type of dwelling, room stress and dwelling satisfaction are also known to impact moving intentions. Residents of apartments are generally less satisfied with their dwelling and are therefore more likely to have a moving intention compared to residents of single-family dwellings (Parkes and Kearns, 2003; Van Ham and Feijten, 2008). Room-stress (ratio persons per room) is also known to impact moving intentions: households experiencing crowding are, besides being less satisfied with the dwelling, also more likely to have moving intentions than households with a low level of room-stress (Van Ham and Feijten, 2008; Clark and Ledwith, 2006). In many mobility studies dwelling satisfaction is found to have a major impact on moving intentions (Clark and Dieleman, 1996; Kirschenbaum, 1983; Lu, 1998). The more satisfied people are the less likely they are to express the intention to move. The time people have lived in their current house and neighbourhood is also found to be a predictor of moving intentions. Parkes and Kearns (2003; see also Lu, 1998) found that people residing longer than 5 years in their neighbourhood are more likely to leave the neighbourhood than people who have stayed in the area for 5 years or less.

\section{Data collection and methods}

To test our hypotheses we used individual level data from our own survey specifically designed to understand the relationship between neighbourhood reputations and different forms of behavioural responses. The survey was carried out in the spring of 2006, in the city of Utrecht in the Netherlands. Utrecht is a compact city with just over 281,000 residents (GBA City of Utrecht, 2006), and has a diverse range of neighbourhoods in terms of population composition. The survey data contains information on individual and household characteristics, including information on housing, the perceived reputation of the neighbourhood, general satisfaction with the area, and moving intentions. The survey was carried out using a random sample of addresses in 24 Utrecht neighbourhoods. These neighbourhoods consist of 69 percent of the total Utrecht population. The neighbourhoods were selected on the basis of a small telephone survey. In each sampled household, the head of the household, or his/her partner, were asked to fill out a questionnaire. Both the distribution and collection of questionnaires took place in person. The neighbourhood Kanaleneiland with the worst reputation in the city - was over sampled to allow more in-depth analyses in future research. Because of the oversampling we weighted the data. 
For the analysis we selected all respondents between 18 and 94 years old, excluding people living in institutions. We also excluded cases with missing information on key variables. This selection resulted in a sample of 1,339 respondents. Since residents are likely to define their neighbourhood-borders in different ways, we did not pre-define neighbourhoods in our questionnaire. Respondents decided what to consider as their neighbourhood. According to several authors (Lee et al., 1994; Lu, 1998) using pre-defined neighbourhoods would probably lead to a distortion of the empirical findings.

\section{Dependent and independent variables}

We constructed a binary dependent variable 'intention to move out of the neighbourhood' by combining two survey questions (a) "Do you plan to move within the next two years?" (b) "Are you planning to move within the neighbourhood?". Respondents who answered the first question with "yes" and the second question with "no" were considered to have the intention to leave the neighbourhood (1) while all others were considered not to have the intention to leave (0). According to this definition, 299 respondents (22.3 percent) had the intention to leave their neighbourhood. Since the dependent variable was binary we used logistic regression models. Because individual respondents are clustered in neighbourhoods we used cluster correction to correct for potential bias in the standard errors of some coeffients.

\section{[Table 1 around here]}

Table 1 gives variable summary statistics for the dependent and independent variables in our model. For dummy variables, the absolute and relative number of respondents in the category of interest is given. The first variable in the table is the dependent variable, followed by a range of individual and household variables: gender; age (1994); household type in 5 categories; ethnicity; level of education in three categories; employment status; monthly household income in Euros; and tenure (own or rent). The next set of variables consists of housing and neighbourhood related characteristics: satisfaction with the dwelling (scale 1 to 10); persons per room ratio; type of house (single-family dwelling or flat/apartment); length of residency in four categories. Furthermore, four variables representing different aspects of the neighbourhood are included: percentage non-western immigrants, average household income per year, crime rates and housing density.

Perceived reputation of the neighbourhood is measured by using the survey question: "Please indicate on a 5 point scale (very negative to very positive), how you think that other city residents assess the reputation of your neighbourhood?". Two variables indicate the perceived level of choice people had on the housing market: choice of dwelling and choice of neighbourhood. The two variables indicating people's sensitivity for social status were based on ten statements (see Appendix 1, Table A1) and Principal components analysis (PCA). The first component refers to how important the neighbourhood as status symbol is to an individual. The second component refers to the weight an individual assigns to social status in general. For both variables a high score indicates strong sensitivity to social status. Interestingly, more respondents appear to be sensitive to the status of the neighbourhood than to general social status. Neighbourhood satisfaction was measured on a ten-point scale ranging from low (1) to high (10) satisfaction.

Two measures of neighbourhood attachment were used: an emotional component based on PCA and a set of variables measuring social contacts (functional component). The emotional component, a ratio variable, is based on four statements 
(see Appendix 1, Table A2), which refer to feeling attached to the neighbourhood and the identification with the neighbourhood. A high score on the component indicates positive emotional feelings to the neighbourhood. Three variables measure social contacts in the neighbourhood: most friends live in neighbourhood; presence of family in the neighbourhood and making a regular chat with neighbours. Finally, formal participation in neighbourhood organisations is measured by participation in a neighbourhood committee and/or neighbourhood organisation.

\section{Results}

[Table 2 around here]

As mentioned in the literature review, perceived reputation, neighbourhood satisfaction and neighbourhood attachment are related concepts. Table 2 shows correlations between these three attitudinal concepts and correlations between the three concepts and a set of objective neighbourhood characteristics. The size of the correlations does not indicate a high risk of multicollinearity and confirms that the concept of perceived neighbourhood reputation truly differs from the concept of neighbourhood satisfaction. ${ }^{3}$ The highest correlation in the table is between neighbourhood satisfaction and neighbourhood attachment $(\mathrm{r}=0.643$, with a common variance of only 41 percent). The results in Table 2 show that perceived reputation is correlated with objective neighbourhood characteristics: neighbourhood crime level shows the lowest correlation $(\mathrm{r}=-0.274)$ and the percentage of non-western immigrants shows the highest correlation $(r=-0.608)$. Housing density and average household income are both moderately correlated with perceived neighbourhood reputation. A previous study by the authors (Permentier et al., 2007) found that both ethnic composition and socio-economic status of the neighbourhood were significant predictors of perceived neighbourhood reputation when controlling for several individual and other neighbourhood characteristics.

[Table 3 around here]

Table 3 shows the results of 6 logistic regression models estimating people's intention to leave their neighbourhood. The table shows the beta coefficients, standard errors, levels of significance and exponentiated coefficient $(\operatorname{ExpB})$ for each variable. In every model a new block of variables is included: Model 1 includes individual, household and dwelling variables; in Model 2 neighbourhood variables are added; in Model 3 perceived neighbourhood reputation is added; Model 4 includes status-sensitivity variables and dwelling and neighbourhood choice variables to control for selection effects; in Model 5 satisfaction with the neighbourhood is added; and finally in Model 6 neighbourhood attachment and neighbourhood participation are included.

Model 1 has a significantly better fit than a model with only a constant. As expected, the older people are, the less likely they are to have the intention to move out of their neighbourhood. We did not find evidence for a non-linear effect of age. Individuals who have lived between 4-7 years in their neighbourhood are more likely to have a moving intention, compared to individuals who have lived three years or less in their neighbourhood. Interestingly, those who have lived 8 years and more in their neighbourhood do not significantly differ from those who have lived three years

\footnotetext{
${ }^{3}$ In our models we have studied the possible impact of multicollinearity on our results by means of Variance Inflation Factors (VIF). The highest VIF-score is 4.46 for percentage non-western immigrants, which is deemed acceptable (greater than 10 is generally seen as problematic), indicating no evidence of multicollinearity.
} 
or less in their neighbourhood. No significant effects were found for gender, ethnicity, level of education, employment status, room stress and dwelling type. Income was found to have a positive effect on moving intentions: those with a high income are more likely to express the intention to leave the neighbourhood than those with lower incomes. As expected, people who are satisfied with their dwelling are much less likely to express a moving intention than individuals who are dissatisfied with their current dwelling. Owner-occupancy has no significant effect on moving intentions, which is caused by the inclusion of the general dwelling satisfaction variable. In a model without the latter, the effect of owner-occupancy is negative and significant (result not shown), which reflects the fact that homeowners are generally more satisfied with their dwelling than renters (see also Parkes and Kearns, 2003; Van Ham and Feijten, 2008).

In Model 2 several objective neighbourhood characteristics are added to the model, which leads to a significant improvement of the model compared to Model 1. The addition of neighbourhood characteristics causes the Nagelkerke R Square to increase to 0.157 . The results show that with an increasing proportion of non-western immigrants in the neighbourhood, people are more likely to have the intention to leave their neighbourhood. Neither the neighbourhood socio-economic status, nor the neighbourhood housing density or neighbourhood crime rates have a significant effect on people's intention to leave their neighbourhood. Additional analyses (not shown) showed that in a model without the percentage of ethnic minorities in the neighbourhood, neighbourhood socio-economic status and housing density have a significant negative effect on moving intentions. The inclusion of objective neighbourhood variables has an impact on the effects of several individual and household characteristics. After controlling for these variables, couples with children appear to be less likely to have the intention to move than others, while a high level of education and a high person per room ratio have a positive impact on the likelihood to have a moving intention.

In Model 3 the perceived neighbourhood reputation is introduced, the main variable of interest in this paper. Including this variable significantly improves the fit of the model compared with the previous model, and the Nagelkerke R Square increases to 0.185. As expected, those who hold a positive perception of the reputation of their neighbourhood are less likely to have a moving intention than people who perceive the reputation of their neighbourhood to be negative. After controlling for perceived neighbourhood reputation the effect of the ethnic composition of the neighbourhood is no longer significant. This indicates that neighbourhood characteristics only have an indirect effect on moving intentions through perceived neighbourhood reputation. Earlier findings by Permentier et al. (2007) already suggested that ethnic composition is a significant and strong predictor of perceived reputation.

In model 4 a set of variables that control for selection effects are introduced. This is a unique feature of our models as many previous studies of moving intentions omit these, mainly because of limitations of the data used. These variables measure the degree of perceived dwelling- and neighbourhood choice and sensitivity to neighbourhood status and status in general. By including these variables we control the effect of perceived reputation as found in Model 3 for self-selection into neighbourhoods linked to neighbourhood reputation and status. Compared to the previous model, Model 4 has a significantly better fit, and the Nagelkerke R Square increases to 0.209. People who moved into their dwelling and neighbourhood of choice are less likely to express the intention to move out of their neighbourhood than people who did not experience this level of choice. The results also show that people who are sensitive to the status of neighbourhoods are far more likely to have the 
intention to leave their neighbourhood than people who are not sensitive to neighbourhood status. ${ }^{4}$ Sensitivity to general social status on the other hand does not appear to be relevant as it has no significant impact on the intention to leave. The perceived reputation variable and sensitivity to neighbourhood status variable are significantly positively correlated $(\mathrm{r}=0.182)$, indicating that residents with a perceived positive reputation of their neighbourhood are also those who are more likely to be particularly sensitive to area status. Additional regression analyses (not shown) indicate that especially ethnic minorities and high-income groups are sensitive to the neighbourhood's status. It is highly notable that controlling for selection effects has no significant effect on the coefficient of perceived neighbourhood reputation.

In model 5 satisfaction with the neighbourhood is added to the model to test the hypothesis that perceived reputation has an effect on moving intentions on top of neighbourhood satisfaction. The addition of this variable results in a significant improvement of the model compared to model 4 and the Nagelkerke R Square increases to 0.220. As expected, people who are satisfied with their neighbourhood are less likely to express an intention to leave the neighbourhood than people who are dissatisfied. Controlling for neighbourhood satisfaction has a clear impact on the effect of perceived neighbourhood reputation: the coefficient drops although it is still strongly significant. This is fascinating as it shows that the concept of perceived neighbourhood reputation as introduced in this paper is an important addition to more established explanations of residential mobility.

Finally, in model 6 two more sets of variables are added to the model. First, measures of neighbourhood attachment are included, and second a measure of neighbourhood participation is included. Again, the fit of the model improves significantly (Nagelkerke $\mathrm{R}$ Square=0.260). The neighbourhood attachment component has the expected positive effect on moving intensions. Residents who feel strongly emotionally attached to their area of residence are much less likely to express an intention to move compared to residents who lack such attachment. Having a social network within the neighbourhood seems only relevant with regard to the presence of friends and contact with the direct neighbours. People who have most of their friends in the neighbourhood and/or who have contact with their neighbours on a regular base are less inclined to leave the neighbourhood. The presence of family appears not to be relevant in this respect. Residents who participate in the neighbourhood do not differ significantly regarding the intention to move, compared to those who do not participate.

After controlling for attachment and neighbourhood participation, the effects of age and couples with children is reduced while neighbourhood choice is no longer significant. This suggests that older respondents, couples with children and those who were free in their choice of neighbourhood are more attached to their neighbourhood, both emotionally and behaviourally, than young respondents, single-person households and respondents without freedom in their choice of neighbourhood. Most spectacularly, after including neighbourhood attachment, also the effect of neighbourhood satisfaction disappears. This indicates that satisfaction is likely to be channelled through the emotional neighbourhood attachment variable: residents who feel attached to the neighbourhood are also the ones most satisfied with their neighbourhood. Again, the effect of the perceived neighbourhood reputation on moving intention drops a little, but remains significant.

\footnotetext{
${ }^{4}$ As it may be expected that a poor perceived neighbourhood reputation mainly affects moving intentions for those who are sensitive to the social status of neighbourhoods, we also included the interaction term perceived neighbourhood reputation*sensitivity to neighbourhood social status (not shown). This interaction effect turned out to be not significant and was therefore removed from the model.
} 
We have seen that with every block of variables added to the model, the effect of the perceived reputation decreases, but it does not disappear. This is a strong indication that the concept of (perceived) neighbourhood reputation adds to our understanding of moving intentions.

\section{Discussion}

In this study we have analysed the effect of perceived neighbourhood reputations on peoples' intention to leave their neighbourhood. Within the behavioural model of residential mobility underlying this study we assumed that the behaviour of residents is more likely to be affected by the neighbourhood reputation as perceived by residents than by the shared view of other city residents, the external reputation (see also Lee et al., 1994). Our study contributed both theoretically and empirically to the residential mobility literature. We extended the existing conceptual framework of residential mobility by introducing the concept of perceived neighbourhood reputation and hypothesised that reputation has an effect on moving intentions on top of more established factors such as neighbourhood satisfaction. The empirical innovation of this paper is that we were able to explicitly include a measure of neighbourhood reputation and control our models for several measures of self-selection into neighbourhoods.

We showed that perceived reputation of the neighbourhood is a significant predictor of mobility intentions, even after controlling for general satisfaction with the neighbourhood, neighbourhood attachment and measures of self-selection. The results show that even though a person might be satisfied, or even attached to his or her neighbourhood, a perceived poor neighbourhood reputation can still induce the intention to move out of the neighbourhood. Interestingly, we found that after controlling for perceived neighbourhood reputation the effect of the ethnic composition of the neighbourhood was no longer significant. This indicates that people perceive ethnic concentration neighbourhoods as having a negative reputation, which is in line with earlier findings (Permentier et al., 2007).

The results also show that moving intentions are strongly influenced by the degree of emotional attachment residents have to their neighbourhood. Residents who are attached to their neighbourhood are less likely to state an intention to leave their neighbourhood. Interestingly, after controlling for neighbourhood attachment (and participation) the effect of neighbourhood satisfaction is no longer significant. This implies that those who are satisfied with their neighbourhood are most likely also attached to their neighbourhood. Apparently, neighbourhood attachment is a more important predictor of the intention to leave the neighbourhood than neighbourhood satisfaction, a variable traditionally used in residential mobility studies.

The results of this study indicate that policies aimed at creating residentially stable neighbourhoods will be more successful if they can increase the level of neighbourhood attachment of the residents. Further, the results indicate the importance of improving the (perceived) reputation of deprived neighbourhoods. Residents who have a negative perception of the neighbourhood's reputation are more likely to express the intention to leave their neighbourhood. These intentions might translate into actual residential mobility, especially among those who have the most resources. Changing the underlying causes of the perceived reputation of a neighbourhood, in addition to improving neighbourhood attachment, could influence more affluent residents to stay, thus creating a more sustainable neighbourhood with socially upward mobile residents. 
Permentier et al. (2007) have shown that especially the socio-economic status of neighbourhoods, the ethnic composition and crime rates are important in impacting perceived reputation. Of these three characteristics, reducing crime rates would be easiest to achieve. Changing the socio-economic status and ethnic composition of neighbourhoods would pose more difficulties (Musterd, 2008). First, policies aimed at creating socially mixed neighbourhoods are controversial (social engineering) because they appear to be at odds with ideas of social equity and individual choice (Crump, 2002). Displacement of residents can also result in the break down of important social structures in neighbourhoods because many of the existing residents are not able to return to their neighbourhood (Clampet-Lundquist, 2004). The resulting 'forced' new mix of residents can result in tension between old and new residents and to a (further) decline of social cohesion (Joseph et al., 2007; Van Beckhoven and Van Kempen, 2003). Second, there is evidence that artificially created socially mixed neighbourhoods will not be very sustainable because of selective mobility in and out of neighbourhoods. Van Ham and Feijten (2008) and Van Ham and Clark (forthcoming) have shown that residents (have the wish to) move away from neighbourhoods where the neighbourhood socioeconomic mix does not match their own characteristics. It is very ironic that creating sustainable mixed neighbourhoods might require substantial policy intervention to keep neighbourhoods mixed.

In the situation that the perceived reputation of neighbourhoods is undeserved (i.e. more negative then to be expected on grounds of actual neighbourhood characteristics) reputation management may be implemented (Hastings and Dean, 2003). Stakeholders, such as residents, welfare organisations, councils and prospective residents, should together create a vision of the desired image of the neighbourhood. Subsequently this vision and image can be the leading principle of both renewal plans and communication with non-residents. Public relations are a significant part of this strategy: neighbourhood transformations (both physical, functional and social) should be widely publicised in communication with neighbourhood residents and other city residents.

\section{References}

Ahlbrandt R, Cunningham J, 1979, A New Public Policy for Neighbourhood Preservation (Praeger, New York, NY)

Amérigo M, 2002 "A psychological approach to the study of residential satisfaction", in Residential Environments: Choice, Satisfaction, and Behavior Eds J A Aragonés, G Francescato and T Gärling (Bergin and Garvey, Westport, CT) pp 81 - 99

Bolt G, Torrance M, 2005, Stedelijke herstructurering en sociale cohesie (DGW/NETHUR, Den Haag/Utrecht)

Bolt G, Van Kempen R, 2002, "Moving up or moving down? Housing careers of Turks and Moroccans in Utrecht, the Netherlands" Housing Studies 17401 422

Blokland T, 2000, "Unravelling three of a kind: cohesion, community and solidarity" Netherlands Journal of Social Sciences 3656 - 70

Boehm T, 1981 "Tenure choice and expected mobility" Journal of Urban Economics 10375 - 389

Bolan M, 1997, "The mobility experience and neighborhood attachment" Demography 34225 - 237

Bourdieu P, 1984 Distinction: A Social Critique of the Judgement of Taste (Harvard University Press, Cambridge, MA) 
Bowes A, Dar N, Sim D, 2002, "Differentiation in housing careers: the case of Pakistanis in the UK" Housing Studies 17381 - 199

Brown L A, Moore E G, 1970, "The intra-urban migration process: a perspective" Geografiska Annaler 52b 1 - 13

Buck N, 2001, "Identifying neighbourhoods effects on social exclusion" Urban Studies 382251 - 2275

Bush J, Moffatt S, Dunn C, 2001, "'Even the birds round here cough': stigma, air pollution and health in Teesside" Health \& Place 747 - 56

Clampet-Lundquist S, 2004, "Hope VI relocation: Moving to new neighborhoods and building new ties" Housing Policy Debate 15415 - 447

Clark W A V, Deurloo M C, Dieleman F M, 2006, "Residential mobility and neighbourhood outcomes" Housing Studies 21323 - 342

Clark W A V, Dieleman F M, 1996 Households and Housing; Choice and Outcomes in the Housing Market (Center for Urban Policy Research, New Brunswick, $\mathrm{NJ})$

Clark W A V, Ledwith V, 2006, "Mobility, Housing Stress, and Neighborhood Contexts: Evidence from Los Angeles" Environment and Planning A 381077 $-1093$

Coleman R P, Neugarten B L, 1972 Social Status in the City (Jossey-Bass, San Francisco, CA)

Crowder K, 2000, "The racial context of white mobility: An individual-level assessment of the white flight hypothesis" Social Science Research 29223 257

Crump J, 2002, "Deconcentration by demolition: public housing, poverty, and urban policy" Environment and Planning D: Society and Space 20581 - 596

Curtis R F, Jackson E F, 1977, Inequality in American communities (Academic Press, New York, NY, San Francisco, CA London)

De Jong G F, Fawcett J, 1981, "Motivations for migration: An assessment and valueexpectancy research model", in Migration Decision Making: Multidisciplinary Approaches to Microlevel Studies in Developed and Developing Countries Eds G F De Jong, R W Gardner (Pergamon Press, New York, NY) pp 13 - 58

Dekker, K., \& Bolt, G. (2005). Social cohesion in post war estates in the Netherlands: differences between social-economic and ethnic groups Urban Studies 42, 2447-2470.

Dekker K, 2007, "Social capital, neighbourhood attachment and participation in distressed urban areas. A case study in the Hague and Utrecht, the Netherlands" Housing Studies 22355 - 379

Feijten P, Van Ham M, forthcoming, "Neighbourhood change....reason to leave?" Urban Studies

Festinger L, 1954 “A theory of social comparison processes" Human Relations 7 117140

Festinger L, 1957 A Theory of Cognitive Dissonance (Stanford University Press, Stanford, CA)

Firey W, 1945, "Sentiment and symbolism as ecological variables" American Sociological Review 10140 - 148

Forrest R, Kearns A, 2001, "Social cohesion, social capital and the neighbourhood" Urban Studies 382125 - 2143

Freeman L, 2000, "Minority housing segregation: a test of three perspectives" Journal of Urban Affairs 2215 - 35

Galster G, 1987 Homeowners and Neighborhood Reinvestment (Duke University Press, Durham, NC, London) 
Galster G C, 1999, "The evolving challenges of fair housing since 1968: Open housing, integration, and the reduction of ghettoization" Cityscape: A Journal of Policy Development and Research 4123 - 138

GBA City of Utrecht, 2006 Buurtmonitor City of Utrecht, http://utrecht.buurtmonitor.nl/

Goffman E, 1963 Stigma: Notes on the management of spoiled identity (Prentice Hall, New York, NY)

Guest A M, Cover J K, Matsueda R L, Kubrin C E, 2006, "Neighourhood context and neighbouring ties" City \& Community 5363 - 385

Harris D R, 1999, "Property values drop when blacks move in, because. Racial and socioeconomic determinants of neighborhood desirability" American Sociological Review 64461 - 479

Hastings A, Dean J, 2003, "Challenging images: tackling stigma through estate regeneration" Policy \& Politics $31171-184$

Hirschman A O, 1970 Exit, Voice and Loyalty: Responses to Decline in Firms, Organizations and States (Harvard University Press, Cambridge, MA)

Joseph M L, Chaskin R J, Webber H S, 2007 "The theoretical basis for addressing poverty through mixed-income development" Urban Affairs Review 42369 409

Kearns A, Parkes A, 2003, "Living in and leaving poor neighbourhood conditions in England" Housing Studies 18827 - 851

Kirschenbaum A, 1983, "Sources of neighborhood residential change: a micro-level analysis" Social Indicators Research 12183 - 198

Krysan M, Farley R, 2002, "The residential preferences of blacks: do they explain persistent segregation" Social Forces 80937 - 980

Lee B A, Oropesa R S, Kanan J W, 1994, "Neighborhood context and residential mobility" Demography 31249 - 270

Logan J R, Collver O A, 1983, "Residents' perceptions of suburban community differences American Sociological Review" 48428 - 433

Lu M, 1998, "Analyzing migration decisionmaking: relationships between residential satisfaction, mobility intentions, and moving behaviour" Environment and Planning A 301473 - 1495

Mead G H, 1934 [1967] Mind, Self, and Society: From the Standpoint of a Social Behaviorist (University of Chicago Press, Chicago, IL)

Mohan J and Twigg L, 2007, "Sense of place, quality of life and local socioeconomic context: Evidence from the survey of English housing, 2002/03" Urban Studies 442029 - 2045

Mulder C, 1993 Migration Dynamics: A Life Course Approach (Thesis Publishers, Amsterdam)

Musterd S, 2008, "Residents' views on social mix: Social mix, social networks and stigmatisation in post-war housing estates in Europe" Urban Studies 45897 915

Overman H G, 2002, "Neighbourhood effects in large and small neighbourhoods" Urban Studies 39117 - 130

Parkes A, Kearns A, 2003, "Residential perceptions and housing mobility in Scotland: An analysis of the longitudinal Scottish house condition survey 1991-96" Housing Studies 18673 - 701

Parkes A, Kearns A, Atkinson R, 2002, "What makes people dissatisfied with their neighbourhood" Urban Studies 392413 - 2438

Permentier M, Bolt G, Van Ham M, 2007, "Determinants of neighbourhood satisfaction and perception of neighbourhood reputation" URU-working paper. Available upon request from author 
Permentier M, Van Ham M, Bolt G, 2008, "Same neighbourhoods....different views? A confrontation of internal and external neighbourhood reputations" Housing Studies 23 833-855

Phillips D, 1998, "Black minority ethnic concentration and dispersal in Britain" Urban Studies 351681 - 1702

Quillian L, 2003, "How long are exposures to poor neighborhoods? The long-term dynamics of entry and exit from poor neighborhoods" Population Research and Policy Review 22221 - 249

Ridgeway C L, 2006 "Status construction theory", in Contemporary Social Psychological Theories Ed P J Burke (Stanford University Press, Stanford, CA) pp $301-323$

SCP, 2007 Aandacht voor de wijk (SCP, Den Haag)

Sharp E, 1984, "Exit, voice and loyalty in the context of local government problems" Western Political Quarterly 767 - 83

South S, Crowder K, Chavez E, 2005, "Exiting and entering high-poverty neighborhoods: Latinos, Blacks and Anglos compared" Social Forces 84873 900

South S, Deane G D, 1993 "Race and residential mobility: Individual determinants and structural constraints" Social Forces 72147 - 167

Speare A, 1974, "Residential satisfaction as an intervening variable in residential mobility" Demography 11173 - 188

Speare A, Goldstein S, Frey W H, 1975, Residential mobility, migration, and metropolitan change (Ballinger, Cambridge, MA)

Suttles G D, 1972 The Social Construction of Communities (The University of Chicago Press, Chicago, IL, London)

Taub R, Taylor D F, Dunham J, 1984 Path of Neighbourhood Change (University of Chicago Press, Chicago, IL)

Taylor M, 1998, "Combating the social exclusion of housing estates" Housing Studies $13819-832$

Temkin K, Rohe W M, 1998, "Social capital and neighborhood stability: an empirical analysis" Housing Policy Debate 961 - 88

Tsfati Y, Cohen J, 2003, "On the effect of the "Third-person effect": perceived influence of media coverage and residential mobility intentions" Journal of Communication $\mathbf{5 3} 711$ - 727

Van Beckhoven E, Van Kempen R, 2003, "Social effects of urban restructuring: a case study in Amsterdam and Utrecht, the Netherlands" Housing Studies 18 $853-875$

Van Ham M, Feijten P, 2008, "Who wants to leave the neighbourhood? The effect of being different from the neighbourhood population on wishes to move" Environment and Planning A 40 1151-1170

Van Ham M, Clark W A V, forthcoming, "Neighbourhood mobility in context: household moves and changing neighbourhoods in the Netherlands" Environment and Planning A

Van Vugt M, Dowding K, John P, Van Dijk E, 2003, “The exit of residential mobility or the voice of political action? Strategies for problem solving in residential communities" Journal of Applied Social Psychology 33321 - 338

Wacquant L J D, 1993, "Urban outcasts: stigma and division in the black American ghetto and the French periphery" International Journal of Urban and Regional Research 19366 - 383

Yinger J, 1999, "Sustaining the fair housing act', Cityscape: A Journal of Policy Development and Research" 493 - 106 
Table 1 Variable summary statistics of the weighted data $(\mathrm{N}=1,339)$

\begin{tabular}{|c|c|c|c|}
\hline 然 & $\mathbf{N}(\%)$ & Mean (S.d.) & Min./Max. \\
\hline Intention to leave neighbourhood (dependent) & $299(22.3)$ & & \\
\hline Female & $709(54.1)$ & & \\
\hline Age & & $44.35(14.81)$ & 19-94 \\
\hline \multicolumn{4}{|l|}{ Household type } \\
\hline Single person household & $364(27.2)$ & & \\
\hline Single parent household & $74 \quad(5.5)$ & & \\
\hline Couple & $436(32.6)$ & & \\
\hline Couple with children & 385 (28.7) & & \\
\hline Other & $80 \quad(6.0)$ & & \\
\hline \multicolumn{4}{|l|}{ Ethnicity } \\
\hline Non-western ethnicity & $166(12.4)$ & & \\
\hline Native Dutch/Western ethnicity & $1,173(87.6)$ & & \\
\hline \multicolumn{4}{|l|}{ Level of education } \\
\hline Low & $284(21.2)$ & & \\
\hline Middle & $374(28.0)$ & & \\
\hline High & $681(50.8)$ & & \\
\hline Not employed & $429(32.1)$ & & \\
\hline Monthly|household income $(* € 100)$ & & $22.33(9.58)$ & $1.8-38$ \\
\hline Owner-occupant & $783(58.5)$ & & \\
\hline Dwelling satisfaction & & $7.55(1.40)$ & $1-10$ \\
\hline Persons/per room-ratio & & $0.60(0.30)$ & $0.1-2$ \\
\hline Flat/apartment & $399(28.8)$ & & \\
\hline \multicolumn{4}{|l|}{ Length of residency } \\
\hline Living in neighbourhood 0-3 years & $362(27.0)$ & & \\
\hline Living in neighbourhood 4-7 years & $322(24.1)$ & & \\
\hline Living in neighbourhood $8-16$ years & $325(24.3)$ & & \\
\hline Living in neighbourhood 17 years and over & $330(24.6)$ & & \\
\hline NBH Percentage non-western immigrants & & $27.37(17.67)$ & $5.35-73.43$ \\
\hline NBH Average household income (year) & & $28.47(5.12)$ & $23.3-45.0$ \\
\hline NBH Crime rates & & $112.87(30.55)$ & $13.7-174.9$ \\
\hline NBH Housing density & & $3,212.88(1047.29)$ & $928-5,546$ \\
\hline Perceived neighbourhood reputation & & $3.2(1.0)$ & $1-5$ \\
\hline Current dwelling first choice & $974(72.8)$ & & \\
\hline Current neighbourhood first choice & $371(27.8)$ & & \\
\hline Sensitivity to social neighbourhood status & & 0 & $-3.4-2.7$ \\
\hline Sensitivity to general social status & & 0 & $-2.7-4.1$ \\
\hline Neighbourhood satisfaction & & $6.99(1.52)$ & $1-10$ \\
\hline Neighbourhood attachment (emotional) & & 0 & $-2.5-1.8$ \\
\hline Most friends live in neighbourhood & $102(7.6)$ & & \\
\hline Family lives in neighbourhood & $313(23.4)$ & & \\
\hline Contact with neighbours & $1,038(77.6)$ & & \\
\hline Member of neighbourhood committee & $127(9.5)$ & & \\
\hline
\end{tabular}

Source: Own survey, 2006 
Table 2 Zero-order correlations between different attitudinal variables and between different neighbourhood characteristics
(1)
(2)
(3)
(4)
(5)
(6)
(1) Perceived NBH reputation
(2) Neighbourhood satisfaction
(3) Neighbourhood attachment
(5) NBH Percentage Non-western immigrants
(6) NBH Average household income
(7) NBH Crime

0.583

0.563

$0.643 \quad--$

0.325

0.215

0.292

$-0.608$

$\begin{array}{llll}-0.498 & -0.424 & -0.357 & --\end{array}$

0.464

0.381

0.259

$-0.242$

$-0.274$

$-0.199$

$-0.106$

0.310

$-0.557 \quad--$

Source: Own survey, 2006 
Constant

Female $(r e f=$ male $)$

Age

Household type (ref=single)

Single parent household

Couple

Couple with children

Other

Non-western immigrant (ref=other)

Level of education ( $r$ ef=low)

Middle education

High education

Not employed (ref=employed)

Household income

Owner-occupant

Dwelling satisfaction

Person/room ratio

Length of residency $(\mathrm{ref}=<4)$

4-7 years

8-16 years

17 and more

NBH Percentage Non-western immigrants

NBH Average household income

NBH Crime rates

NBH Housing density

Current dwelling first choice

Current neighbourhood first choice

Sensitivity to social neighbourhood status

Sensitivity to general social status

Moighbourhood attachment (emotional)

Family lives in neighbourhood (ref=no)

Contact with neighbours (ref=no)

Member of neighbourhood committee (ref=no)

Log-likelihood

Improvement (wald)

Initial
$-653.43$

$331.47 \mathrm{p}=0.000$

0.127 $\begin{array}{rr}-0.754 & 0.526 \\ 0.008 & 0.239\end{array}$

$-0.189 \quad 0.306$

$\begin{array}{ll}-0.077 & 0.165\end{array}$
Flat/apartment ( $r$ ef=other $)$

Perceived neighbourhood reputation

Neighbourhood satisfaction

Nagelkerke R-Square

$\begin{array}{ll}\text { MODEL } 2 & \\ \text { B } & \text { EXP(B) }\end{array}$

$\begin{array}{lr}\text { B } & \text { S.E. } \\ 0.595 & 1.022\end{array}$

$\begin{array}{ll}-0.049 & 0.201\end{array}$

$-0.0240 .007^{* * *}$

0.952

(B)

MODEL 3

$\begin{array}{ll}0.237 & 0.312\end{array}$

$\begin{array}{ll}-0.042 & 0.350\end{array}$

$\begin{array}{ll}-1.012 & 0.486^{* *} \\ 0.127 & 0.248\end{array}$

$\begin{array}{ll}0.127 & 0.248\end{array}$

$\begin{array}{ll}-0.474 & 0.303\end{array}$

0.976

1.268

0.959

0.363

0.827

$\begin{array}{ll}0.334 & 0.247 \\ 0.066 & 0.207\end{array}$

0.926

1.397

$\begin{array}{ll}-0.052 & 0.174\end{array}$

$0.5480 .272^{\star *}$

$\begin{array}{ll}0.059 & 0.215\end{array}$

$\begin{array}{ll}0.041 & 0.017^{* *}\end{array}$

$\begin{array}{ll}-0.228 & 0.187\end{array}$

$-0.2450 .061^{\text {*** }}$

$0.7250 .342^{\star \star}$

$\begin{array}{ll}-0.114 & 0.263\end{array}$

1.135

0.622

0.950
1.729

1.729

1.060
1.042
0.796

0.796

0.783

2.065

0.892

$\begin{array}{lll}0.483 & 0.258^{*} & 1.621\end{array}$

$\begin{array}{lll}0.408 & 0.262 & 1.504\end{array}$

$\begin{array}{lll}0.417 & 0.260 & 1.518 \\ 0.464 & 0.261 * & 1.590\end{array}$

$0.4640 .261^{*}$

$\begin{array}{lll}0.210 & 0.482\end{array}$

$0.0180 .005^{* * *}$

$\begin{array}{ll}-0.027 & 0.021\end{array}$

1.590

1.590
1.234
1.018

1.018

$0.001 \quad 0.003$

$0.000 \quad 0.000$

1.001

1.001
1.000

$\begin{array}{lc}\text { B } & \text { MODEL 3 } \\ 0.888 & \text { S.E. } \\ 1.022 \\ -0.040 & 0.205\end{array}$

$\operatorname{EXP}(B)$

MODEL 4

$\begin{array}{lll}-0.040 & 0.205 & 0.961\end{array}$

$-0.0230 .007^{\star \star *}$

0.961
0.977

$0.555 \quad 1.100$

$\begin{array}{ll}-0.012 & 0.244\end{array}$

$-0.0200 .006^{\star * *}$

0.988

\begin{tabular}{lll|ll}
0.260 & 0.373 & 1.300 & 0.262 & 0.386
\end{tabular}

$\begin{array}{ll}-0.092 & 0.343\end{array}$

$\begin{array}{cc}-1.038 & 0.459^{* *} \\ 0.177 & 0.276\end{array}$

$\begin{array}{ll}0.177 & 0.276\end{array}$

0.912

0.912
0.354

1.193

0.716

$\begin{array}{rr}-0.072 & 0.357\end{array}$

$\begin{array}{ll}-1.0120 .473^{* *} \\ 0.138 & 0.231\end{array}$

$0.138 \quad 0.231$

$\begin{array}{ll}-0.476 & 0.392\end{array}$

$-0.053 \quad 0.165$

$0.5200 .290^{*}$

$\begin{array}{ll}0.076 & 0.225\end{array}$

$0.0430 .017^{* *}$

$\begin{array}{ll}-0.156 & 0.203\end{array}$

$-0.2250 .065^{\star \star}$

$0.7140 .334^{\star *}$

$\begin{array}{ll}-0.034 & 0.280\end{array}$

0.948

1.682

\begin{tabular}{ll}
$-0.170 \quad 0.167$ \\
\hline
\end{tabular}

$0.457 \quad 0.298$

$0.097 \quad 0.212$

$0.0410 .018^{\star *}$

$\begin{array}{ll}-0.127 & 0.210\end{array}$

$\begin{array}{ll}-0.166 & 0.066^{* *} \\ 0.716 & 0.348 *\end{array}$

$0.7160 .348^{* *}$

$\begin{array}{ll}-0.060 & 0.230\end{array}$

\begin{tabular}{ll}
0.347 & 0.274 \\
\hline
\end{tabular}

$0.434 \quad 0.265$

$\begin{array}{ll}0.161 & 0.465\end{array}$

0.0090 .006

$0.005 \quad 0.018$

$0.000 \quad 0.003$

$\begin{array}{rl}0.000 & 0.000 \\ -0.501 & 0.096^{\star * *}\end{array}$

1.416

$\begin{array}{ll}0.407 & 0.279\end{array}$

$\begin{array}{ll}0.485 & 0.266^{*}\end{array}$

$\begin{array}{ll}0.485 & 0.266 \\ 0.226 & 0.428\end{array}$

$\begin{array}{ll}0.226 & 0.428 \\ 0.008 & 0.006\end{array}$

$\begin{array}{ll}0.007 & 0.019\end{array}$

$\begin{array}{ll}0.001 & 0.003\end{array}$

$\begin{array}{cc}0.000 & 0.000 \\ -0.486 & 0.083\end{array}$

0.606

$\begin{array}{lll}-0.486 & 0.083^{* * *} & 1.000 \\ -0.467 & 0.236 * * & 0.627\end{array}$

$\begin{array}{lll}-0.467 & 0.236^{* *} & 0.615 \\ -0.504 & 0.277^{*} & 0.627\end{array}$

$\begin{array}{lll}-0.504 & 0.277^{*} & 0.604\end{array}$

0.604
1.171

$\begin{array}{ll}0.173 & 0.178\end{array}$

1.188

Note: Key-variables are shaded grey

$*=\mathrm{p}<0.10 ; * *=\mathrm{p}<0.05 ; * * *=\mathrm{p}<0.01$ 
Table 3 (continued)

\begin{tabular}{|c|c|c|c|c|c|c|}
\hline \multirow[b]{3}{*}{ Constant } & \multicolumn{3}{|c|}{ MODEL 5} & \multicolumn{3}{|c|}{ MODEL 6} \\
\hline & B & S.E. & $\operatorname{EXP}(B)$ & B & S.E. & $\operatorname{EXP}(B)$ \\
\hline & 0.880 & 1.169 & & -1.074 & 1.671 & \\
\hline Female $(\mathrm{ref}=\mathrm{male})$ & -0.007 & 0.242 & 0.993 & 0.031 & 0.254 & 1.032 \\
\hline Age & -0.021 & $0.007^{\star * *}$ & 0.979 & -0.017 & $0.007^{* * *}$ & 0.984 \\
\hline \multicolumn{7}{|l|}{ Household type (ref=single) } \\
\hline Single parent household & 0.224 & 0.390 & 1.250 & 0.163 & 0.348 & 1.177 \\
\hline Couple & -0.095 & 0.354 & 0.909 & -0.192 & 0.339 & 0.825 \\
\hline Couple with children & -0.998 & $0.486^{\star *}$ & 0.369 & -0.895 & $0.457^{*}$ & 0.408 \\
\hline Other & 0.158 & 0.240 & 1.171 & 0.043 & 0.273 & 1.044 \\
\hline Non-western immigrant (ref=other) & -0.456 & 0.409 & 0.634 & -0.293 & 0.392 & 0.746 \\
\hline \multicolumn{7}{|l|}{ Level of education $(\mathrm{ref}=\mathrm{low})$} \\
\hline Middle education & -0.146 & 0.174 & 0.864 & -0.188 & 0.190 & 0.829 \\
\hline High education & 0.503 & 0.307 & 1.653 & 0.554 & 0.373 & 1.741 \\
\hline Not employed (ref=employed) & 0.081 & 0.208 & 1.084 & 0.074 & 0.190 & 1.076 \\
\hline Household income & 0.042 & $0.018^{* *}$ & 1.043 & 0.047 & $0.018^{\star *}$ & 1.048 \\
\hline Owner-occupant & -0.126 & 0.209 & 0.882 & -0.073 & 0.198 & 0.929 \\
\hline Dwelling satisfaction & -0.097 & 0.090 & 0.908 & -0.100 & 0.084 & 0.904 \\
\hline Person/room ratio & 0.720 & $0.335^{\star *}$ & 2.055 & 0.857 & $0.389^{* *}$ & 2.356 \\
\hline Flat/apartment (ref=other) & -0.043 & 0.216 & 0.958 & -0.091 & 0.237 & 0.913 \\
\hline \multicolumn{7}{|l|}{ Length of residency $(r e f=<4)$} \\
\hline 4-7 years & 0.449 & 0.285 & 1.566 & 0.438 & 0.296 & 1.550 \\
\hline $8-16$ years & 0.551 & $0.264^{\star *}$ & 1.736 & 0.646 & $0.286^{* *}$ & 1.907 \\
\hline 17 and more & 0.270 & 0.428 & 1.309 & 0.437 & 0.394 & 1.547 \\
\hline NBH Percentage Non-western immigrants & 0.006 & 0.005 & 1.006 & 0.005 & 0.005 & 1.005 \\
\hline NBH Average household income & 0.014 & 0.022 & 1.014 & 0.017 & 0.030 & 1.017 \\
\hline NBH Crime rates & 0.001 & 0.003 & 1.001 & 0.002 & 0.003 & 1.002 \\
\hline NBH Housing density & 0.000 & 0.000 & 1.000 & 0.000 & 0.000 & 1.000 \\
\hline Perceived neighbourhood reputation & -0.375 & $0.108^{\star * *}$ & 0.687 & -0.298 & $0.110^{\star \star *}$ & 0.742 \\
\hline Current dwelling first choice & -0.452 & $0.249^{*}$ & 0.637 & -0.158 & 0.268 & 0.853 \\
\hline Current neighbourhood first choice & -0.424 & 0.283 & 0.654 & -0.307 & 0.253 & 0.736 \\
\hline Sensitivity to social neighbourhood status & 0.143 & $0.056^{\star * *}$ & 1.154 & 0.173 & $0.074^{* *}$ & 1.188 \\
\hline Sensitivity to general social status & 0.143 & 0.167 & 1.153 & 0.158 & 0.172 & 1.172 \\
\hline Neighbourhood satisfaction & -0.212 & $0.097^{* *}$ & 0.809 & -0.052 & 0.090 & 0.950 \\
\hline Neighbourhood attachment (emotional) & & & & -0.521 & $0.130^{* * *}$ & 0.594 \\
\hline Most friends live in neighbourhood $(r e f=n o)$ & & & & -0.863 & $0.456^{*}$ & 0.422 \\
\hline Family lives in neighbourhood $(r e f=n o)$ & & & & 0.201 & 0.325 & 1.223 \\
\hline Contact with neighbours $(r e f=n o)$ & & & & -0.497 & $0.193^{* * *}$ & 0.608 \\
\hline Member of neighbourhood committee (ref=no) & & & & -0.141 & 0.277 & 0.869 \\
\hline Log-likelihood & -607.14 & & & -586.51 & & \\
\hline Improvement (wald) & 4.79 & $p=0.029$ & & 32.01 & $\mathrm{p}=0.000$ & \\
\hline Nagelkerke R-Square & 0.220 & & & 0.260 & & \\
\hline
\end{tabular}




\section{Appendix 1}

Table A1 Principal component analysis ${ }^{a}$ of statements related to status-sensitivity

\begin{tabular}{lrrr} 
& $\begin{array}{c}\text { Completely) }^{2} \\
\text { agree \% }\end{array}$ & \multicolumn{2}{c}{ Component $^{\mathrm{b}}$} \\
The statements & 47 & 0.774 & 0.019 \\
\hline The reputation of a neighbourhood is important to me & 44 & 0.813 & 0.052 \\
It is important to me to live in a neighbourhood that is known to be a good & & & \\
neighbourhood & 26 & 0.714 & 0.317 \\
I find it important to live in a neighbourhood that suits my status & 23 & 0.734 & 0.332 \\
To me it is important how my neighbourhood is experienced by friends & & & \\
and family & 21 & 0.580 & 0.267 \\
The opinion of my family and friends regarding my neighbourhood is & & & \\
important to me & 22 & 0.161 & 0.674 \\
I want others to know of my achievements & 29 & 0.207 & 0.636 \\
It is important to me what others think or say about me & 4 & 0.087 & 0.762 \\
I like to buy things that impress other people & 22 & 0.136 & 0.685 \\
To climb the social ladder is one of the more important goals in life & 9 & 0.182 & 0.680
\end{tabular}

know

${ }^{a}$ Extraction method: principal component analysis. Rotation method: varimax with Kaiser normalisation. Rotation converged in 3 iterations.

${ }^{\mathrm{b}}$ Cronbach's Alpha of this model is 0.917 , indicating that the model represents the input variables

Source: Own survey, 2006

Table A2 Principal component analysis ${ }^{\mathrm{a}}$ of statements related to neighbourhood attachment

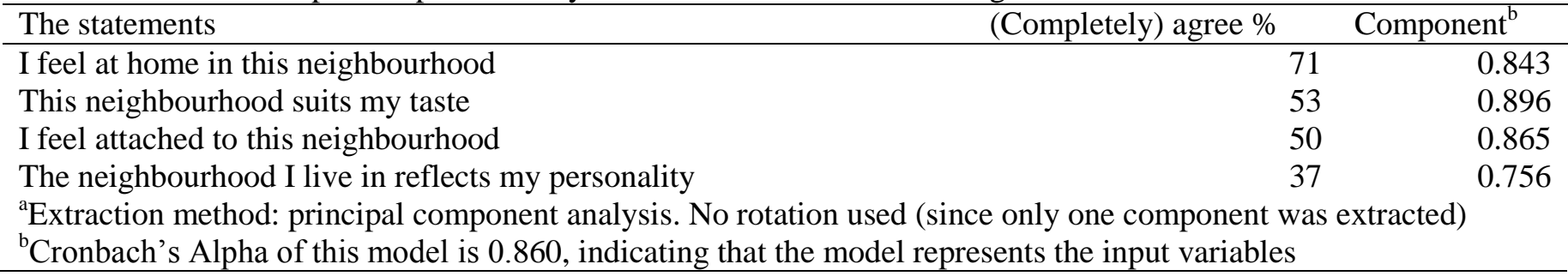

Source: Own survey, 2006 